\title{
ВЛИЯНИЕ ПОДВИЖНОЙ КУЛЬТУРАЛЬНОЙ СРЕДЫ НА ЭКСПРЕССИЮ ТРАНСПОРТЕРОВ ОРГАНИЧЕСКИХ АНИОНОВ В КЛЕТОЧНОЙ ЛИНИИ RРТЕС
}

\author{
В.А. Евтеев, Н.Д. Бунятян, А.Б. Прокофьев \\ НЦЭСМП Минздрава Росии, 2021
}

DOI: 10.19163/MedChemRussia2021-2021-499

Одним из направлений развития моделей для экспериментальной оценки нефротоксичности лекарственных средств (ЛС), является изучение влияния подвижности культуральной среды, так как in vivo клетки эпителия проксимальных почечных канальцев, постоянно подвергаются механическому воздействию, возникающему при движении жидкости. До сих пор недостаточно данных о том, как влияет это воздействие на функциональную активность клеток, в частности на возможности транспорта ими ксенобиотиков.

Методы исследования. Клеточная линия и условия культивирования. Клеточная линия проксимальных почечных канальцев человека RPTEC/TERT1 была получена из банка культур клеток ATCC (\#CRL-4031). Клетки культивировались 7 дней в статичной среде во флаконах $75 \mathrm{~cm}^{2}$ по протоколу рекомендованному АТСС. Далее клетки пересевались на 12-тилучночные планшеты с мембранными вставками 0,4 мкм CorningTranswell.

Перфузия. Эксперимент по перфузии проводился с использованием перфузионной качалки PerfusionRocker Mini (Mimetas, NL) для создания двунаправленного пульсирующего потока, индуцированного наклоном. После посева в планшеты клетки культивировали 3 дня при нормальном потоке, необходимом для пролиферации: угол наклона - $7^{\circ}$, интервал - 8 мин, что соответствует физиологическому значению FSS 2,0 дин/см² и находится в пределах диапазона FSS, использованного в других исследованиях RPTEC при оценке FSS in vivo. На 3-й день после посева среду обновляли и продолжали культивировать 7 дней без пенициллина/стрептомицина уже при более слабом потоке: угол наклона - $2^{\circ}$, интервал - 15 мин, что соответствует пиковому FSS 0,5 дин/см². Такой уровень потока использовался в качестве минимального потока, необходимого для удаления отходов и подачи питательных веществ и кислорода. Среду обновляли каждые 2-3 дня. и помещали при $37^{\circ} \mathrm{C}$ и 5\% $\mathrm{CO}_{2}$ на перфузионную качалку mini, чтобы позволить клеткам дифференцироваться в соответствующем потоке. Было проведено 3 независимых эксперимента.

Измерение экспрессии генов методом ОТ-ПЦР. Было проведено измерение уровня экспрессии генов транспортеров органических анионов: OAT1 (ген SLC22A6) и OAT3 (ген SLC22A8). Кроме экспрессии генов ОАТ-транспортеров, исследовался уровень экспрессии гена $\gamma$-глутатионS-трансферазы ( $\gamma \mathrm{GST})$, которая является одним из показателей дифференцировки линии RPTEC. Также была изучена экспрессия гена, кодирующего один из компонентов плотных межклеточных контактов - клаудин-2 (CLDN2). В качестве референсных генов использовались GAPDH и HPRT1.

Результаты. Было показано, что при культивировании клеточной линии RPTEC/TERT в подвижной среде достоверно увеличивается уровень экспрессии транспортеров органических анионов, что делает такую экспериментальную модель потенциально более чувствительной к токсическому действию ксенобиотиков, в том числе и отрицательно заряженных ЛС, которые являются субстратами ОАТ-транспортеров.

Повышение уровня экспрессии генов глутатион-S-трансферазы и клаудина-2 позволяет сделать вывод о влиянии подвижной среды на дифференцировку клеток RPTEC. Образование плотного клеточного монослоя является необходимым условием при создании экспериментальной модели для тестирования нефротоксичности.

1. E.J. Weber, A. Chapron, B.D. Chapron, J.L. Voellinger, K.A. Lidberg et al. Development of a microphysiological model of human kidney proximal tubule function, Kidney Int. 90 (2016) 627-637.

2. N.Y.C. Lin, K.A. Homan, S.S. Robinson, D.B. Kolesky, N. Duarte, A. Moisan, J.A. Lewis, Renal reabsorption in 3D vascularized proximal tubule models, Proc. Natl. Acad. Sci. U. S. A. (2019).

3. K.A. Homan, D.B. Kolesky, M.A. Skylar-Scott, J. Herrmann, H. Obuobi, A. Moisan, J.A. Lewis, Bioprinting of 3D convoluted renal proximal tubules on perfusable chips, Sci. Rep. 6 (2016). 